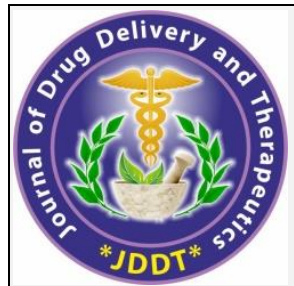

Open $\odot$ Access
Available online on 05.11.2020 at http://jddtonline.info

\section{Journal of Drug Delivery and Therapeutics}

Open Access to Pharmaceutical and Medical Research

(C) 2011-18, publisher and licensee JDDT, This is an Open Access article which permits unrestricted non-commercial use, provided the original work is properly cited

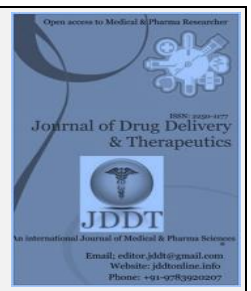

Research Article

\title{
Whether Cord Blood or Venous Blood Procalcitonin Level for Better Prediction of Maternofetal Infections in Algerian Newborns?
}

\author{
Adouani Imene ${ }^{1,2 *}$, Djabi Farida ${ }^{3}$, Hang TaiJun ${ }^{4}$, Guemeche Souad ${ }^{5}$ \\ 1 Department of Biochemistry, Faculty of Nature and Life Sciences, Ferhat Abbas University Setif-1, Setif 19000, Algeria \\ ${ }^{2}$ Department of Pharmacy, Faculty of Medical Sciences, Ferhat Abbas University Setif-1, Setif 19000, Algeria \\ ${ }^{3}$ Laboratory of Molecular Biology, Saadna Abd el Nour Hospital, Setif 19000, Algeria \\ ${ }^{4}$ Center of Drug Quality and Pharmacovigilence, China pharmaceutical university, Nanjing 210000, China \\ ${ }^{5}$ Unit of Epidemiology, Saadna Abd el Nour Hospital, Setif 19000, Algeria
}

\begin{abstract}
This prospective study aims to measure and compare the level of umbilical cord blood and venous blood procalcitonin (PCT) for a better and more rapid prediction of maternofetal infections in Algerian newborns. The study was conducted at the hospital of child and mother of Setif in Algeria from 2016 to 2018. 164 Algerian term suspected newborns born alive to mothers with Maternofetal infection (MFI) risk factors were included. 69 non-infectious newborns born alive to mothers without MFI risk factors served as the control group. The venous blood and cord blood in each group were collected. PCT levels were determined and compared to CRP levels. Receiver operating curves (ROC) were generated to detect the best cut-off values for sensitivity and specificity. Levels of both cord blood and venous blood procalcitonin were significantly higher in the suspected group than those in the control group $(\mathrm{P}<0.05)$. According to the ROC curve, at the cut-off value of cord blood PCT of $0.595 \mathrm{ng} / \mathrm{mL}$, the sensitivity and specificity were $92.3 \%, 91.8 \%$ respectively. At the cut-off value of venous blood PCT of $1.12 \mathrm{ng} / \mathrm{mL}$, the sensitivity and specificity were $100 \%, 80.5 \%$ respectively. The diagnostic value of cord blood PCT for maternofetal infections is higher than venous blood PCT.
\end{abstract}

Keywords: Algerian term newborns, Cord blood, Procalcitonin, Maternofetal infections.

Article Info: Received 18 Aug 2020; $\quad$ Review Completed 27 Sep 2020; $\quad$ Accepted 19 Oct 2020; Available online 05 Nov 2020

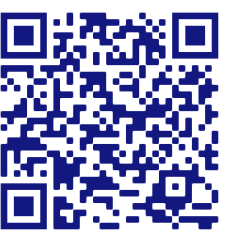

Cite this article as:

Adouani I, Djabi F, Hang T, Guemeche S, Whether Cord Blood or Venous Blood Procalcitonin Level for Better Prediction of Maternofetal Infections in Algerian Newborns?, Journal of Drug Delivery and Therapeutics. 2020; 10(5-s):320-325 http://dx.doi.org/10.22270/jddt.v10i5-s.4567

*Address for Correspondence:

Adouani Imene, Department of Pharmacy, Faculty of Medical Sciences, Ferhat Abbas University Setif-1, Setif 19000, Algeria

\section{INTRODUCTION}

Maternofetal infections (MFI) are early onset infections acquired from the mother by vertical transmission [1] [2]. They are common because of the suboptimal protective immune barriers of the newborn [3] [4] [5] [6]. This kind of infections are still an issue of neonate's survival in Algeria. Neonatologists still challenging many difficulties in confirming the diagnosis and timely starting the treatment of these infections [7] [8] [5]. Diagnosis in Algeria relies on CRP measurement and clinical suspicion based on subtle clinical signs [6] [9][10][7] that can occur in some other diseases. Otherwise, some newborns may be completely asymptomatic at the initial stages of the infection [11]. Therefore, such presentations can lead to a delayed treatment of infected newborns or antibiotic therapy in noninfected cases resulting in many complications [2] [12] [13] [9].
Thus, early and precise identification of MFI is strongly recommended [14] [9].

Blood culture should not be required for diagnosis of MFI in everyday practice because it has several drawbacks [7] [15]. Therefore, the use of biochemical markers is a potential step in the survival of newborns. The properties of an ideal diagnostic biomarker include rapid elevation, acceptable sensitivity as well as excellent specificity [16] [17]. Its capacity to discriminate between etiologies of sepsis and to help in monitoring antibiotic therapy would be valuable characteristics too.

Many biomarkers have been investigated for their utility in the prediction of neonatal infections [2] [8] [13] [14] [15] [16] [18] [19]. They showed some limits and remain unreliable. None of them has been proven to date as an accurate predictive tool [16] [20]. Only C-reactive protein (CRP) and Procalcitonin (PCT) 
have been sufficiently studied [8] [16] [20]. The deep knowledge about CRP is one of the reasons why these classical tests still have its place in the diagnostic setup of neonatal infections [15]. However, its low sensitivity and specificity to detect the infection at an early stage makes it of moderate value for ruling out alone bacterial infections in neonates [2] [20] [21] [22]

Procalcitonin (PCT) has been strongly described as a reliable diagnostic and prognostic marker of neonatal sepsis in more than 13 studies including more than 1086 neonates [13] [23] [24]. Many studies have shown that it is more efficient comparing to CRP because it rises earlier (within 2-4 hours), it helps to differentiate between viral and bacterial etiologies and it aids in guiding antibiotic treatment [2] [9] [13] [25] [26]. Its concentration does not only reflect the presence, but also the intensity of the infection. According to the performed studies PCT cut-offs ranged from 0.5 to $25 \mathrm{ng} / \mathrm{mL}$ [23]. While PCT has shown to be the most promising marker, up to now there are no published studies evaluating PCT for the diagnosis and treatment of neonatal infections in Algeria. Data in the Algerian population are lacking and highly needed.

Therefore, the main objective of this study is to evaluate the performance of both umbilical cord blood and peripheral blood PCT levels in the early prediction of MFI in suspected Algerian term newborns. This study is the first to assess PCT in newborns in Algeria. We attempt to incorporate this marker into the decision algorithm to assist clinicians in the area of diagnosing and treating MFIs, so as PCT could be used effectively as a routine test in our hospital. Secondary objectives were to determine the association between MFI and some risk factors.

\section{POPULATION AND METHODS}

\section{I.1. Patients and study design}

We prospectively studied Algerian term newborns born alive by natural vaginal delivery at the hospital of mother and child of Setif between January 2016 and December 2018. Term birth was defined as delivery at $\geq 37$ weeks gestational age.

The enrolled newborns were classified into two groups. Case group (group I); included suspected newborns born to mothers with at least one MFI risk factor. Control group (group II); included newborns born to mothers without any MFI risk factor. A neonatologist clinically examined the suspected newborns immediately after birth to identify MFI. CRP measurement was done12 hours after birth to confirm MFI.

Newborns presenting noticeable congenital malformations, or born with a low birth weight were excluded from the study.

The study was initiated upon ethical approval by the scientific committee of Ferhat Abbas University Setif-1 (UFAS-1). Parental consent was obtained for each newborn prior to enrollment.

\section{I.2. Methods}

\section{I.2.1. Interrogatory}

After enrollment, mothers were interrogated using a face-toface questionnaire. We have also consulted the medical documents of both the mother and the newborn. The detailed sociodemographic and medico-surgical informations were collected.

In addition to maternal parity, maternal antenatal antibiotherapy, maternal hospitalization during the third trimester of pregnancy and medical devices used during the hospitalization, complete obstetric history to detect

potential risk factors of MFI (PROM, abnormal maternal body temperature during delivery, maternal UTI, malodorous and/or colored amniotic liquid) were noted.

The demographic variables of newborns as birth weight, gestational age at delivery, gender and APGAR score at the 5 th minute were also recorded. All demographic and clinical characteristics of the study are summarized in table.1.

\section{I.2.2. Sample collection and analysis}

The umbilical cord blood samples were collected immediately after delivery for PCT determination only. The peripheral venous blood samples were collected within 2-4 $\mathrm{h}$ and $12 \mathrm{~h}$ after birth for the determination of PCT and CRP respectively. All samples were collected into dry tubes, centrifuged for $10 \mathrm{~min}$ at $3000 \mathrm{r} / \mathrm{min}$ at room temperature within 30 minutes from collection. Then, serum was aliquoted to $2 \mathrm{~mL}$ eppendorf tube and stored at $-20^{\circ} \mathrm{C}$ prior to analysis. Samples were diluted before analyses if necessary.

Samples for the measurement of PCT levels were analyzed following the manufacturer's instructions using an automated enzyme-linked immunofluorescence assay using a commercially VIDAS $®$ BRAHMS PCT ${ }^{\text {TM }}$ (Biomerieux, Germeny). This automat is available at the laboratory of molecular biology, the hospital of child and mother, Setif, Alegeria. It provides a measurement range of $0.05-200$ $\mathrm{ng} / \mathrm{mL}$ and can have results within approximately 20 minutes. CRP levels were determined manually using the latex method using a commercial latex agglutination kit. The samples for CRP determination were tested in dilutions of $1 / 2$.

\section{I.2.3. Statistical analyses}

Data were collected then assessed using SPSS statistics software version 17.0 (SPSS Inc. Chicago, IL, USA). Descriptive statistics were used for neonatal and maternal characteristics. Data were summarized using mean and standard deviation (mean \pm SD) for continuous variables and percent for categorical variables.

The Receiver operating characteristic (ROC) curve was plotted to estimate PCT optimal cutoff points and to examine its diagnostic value, sensitivity and specificity in differentiating non-infected and infected newborns for the diagnosis of MFI. P-value less than 5\% was considered statistically significant. The association between the studied risk factors and the presence of the infection was quantified using Odds ratio. In this study, continuous variables were compared using the t-test or Mann-Whiteny test and categorical data were compared using the khi square test or Fisher exact test.

\section{RESULTS AND DISCUSSION}

In this study, 233 newborns were enrolled. The case group (group I) was composed of 164 suspected newborns. The control group (group II) included 69 apparently healthy newborns. Comparisons were done separately in each group. Venous blood CRP values more than 18 (CRP $\geq 18 \mathrm{mg} / \mathrm{L}$ ) were considered abnormal.

The limited number of our study population could be explained by the challenges we faced to collect the samples at inconvenient hours during the day and night. We only analyzed term newborns in the first 24 hours of life to omit the problem of age-specific differences that may confound the interpretation of PCT values. As prematurity and very low birth weight can highly affect PCT concentrations [16],[27] [28], these cases were excluded from our study. 
In group I, $44.4 \%$ of newborns were female and $55.6 \%$ were male. The gestational age of the newborns in this group ranged from 37 to 43 weeks of gestation. Mean birth weight was $3349.49 \pm 494.43$ grams. Average APGAR score at 5 th minute was $7.85 \pm 0.56$. Fifteen newborns in this group had a respiratory distress at birth. The average of white blood cells count was $15,412 \pm 6,029 / \mathrm{mcl}$. The average of platelet count was $272.968 \pm 62.879 / \mathrm{mcl}$. The average of cord blood PCT levels was $0.560 \pm 1.975 \mathrm{ng} / \mathrm{mL}$. The average of venous blood PCT levels was $2.765 \pm 10.030 \mathrm{ng} / \mathrm{mL}$. $6.1 \%$ of newborns in this group showed a positive values of CRP (CRP $\geq 18 \mathrm{mg} / \mathrm{L})$.

In group II, $53.6 \%$ of newborns were female and $46.4 \%$ were male. The gestational age of the newborns in this group ranged from 37 to 42 weeks of gestation. Mean birth weight was 3376.81 \pm 400.79 grams. Average APGAR score at 5th minute was $8.01 \pm 0.44$. One newborn had a respiratory distress at birth. The average of white blood cells count was $15.557 \pm 5.006 / \mathrm{mcl}$. The average of platelet count was $255.047 \pm 66.231 / \mathrm{mcl}$. The average of cord blood PCT levels was $0.188 \pm 0.153 \mathrm{ng} / \mathrm{mL}$. The average of venous blood PCT levels was $0.296 \pm 0.321 \mathrm{ng} / \mathrm{mL}$. All the newborns in this group showed a negative values of CRP (CRP $<18 \mathrm{mg} / \mathrm{L})$.

The white blood cells and platelet counts were not significantly different in newborns with high suspicion of MFI and in controls $(\mathrm{P}=0.925, \mathrm{P}=0.331$ respectively). CRP levels were significantly different in newborns with high suspicion of MFI and in controls $(\mathrm{P}=0.000)$. The level of cord blood PCT is significantly higher among newborns with lower APGAR $<7 \quad(p=0,010)$, within newborns having a respiratory distress at birth $(\mathrm{p}=0,004)$. Risk of MFI was 3 times higher among newborns with APGAR $<7$ and 5,635 higher among newborns born with a respiratory distress.The levels of PCT were not significantly affected by gender $(p=0.186)$, birth weight $(p=0.669)$ and gestational age $(\mathrm{p}=0.416)$.

Both the mean cord blood procalcitonin and the mean venous blood procalcitonin levels in newborns with high suspicion of MFI were significantly higher than that in the control group $(\mathrm{P}=0.000, \mathrm{P}=0,026$ respectively). In both groups, the mean of venous blood procalcitonin levels were higher than the mean cord blood procalcitonin $(\mathrm{P}<0.005)$. The optimum cut-off value was $0.595 \mathrm{ng} / \mathrm{mL}$ for cord blood PCT. Sensitivity, specificity of cord blood PCT at this cut-off value, were $92.3,91.8$ percent, respectively for the diagnosis of MFI. At a cut-off value of $1.12 \mathrm{ng} / \mathrm{mL}$, venous blood PCT was found to have sensitivity and specificity of $100,80.5$ percent, respectively. Figures 1 and 2 display the ROC curves describing respectively the values of cord blood PCT and venous blood PCT concentrations in the prediction of MFI.

In the last few years, PCT has been investigated as a promising early biomarker in the diagnosis of neonatal infections and different results have been published [17],[27]. In these studies, PCT values ranged from 0.5 to $25 \mathrm{ng} / \mathrm{mL}$ [23], the reported PCT sensitivity for the diagnosis of early onset sepsis was found to be $30-100 \%$ while the specificity was $51-100 \%$ [17]. AUC values were also different from a study to another [29], [30]. The AUC values reported in this paper were better. This variability among the results could be related to many factors such as; the physiological variability, the selected study populations, the criteria used for the diagnosis, the different analytical methods used in each study and the differences in sample timing and cut-off values.

Table 1: Characteristics of studied population (newborns and mothers)

\begin{tabular}{|c|c|c|c|c|c|}
\hline \multicolumn{2}{|r|}{ Characteristics } & Group I & Group II & P value & OR \\
\hline \multirow{4}{*}{ 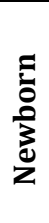 } & Gestational age (weeks) & $39,41 \pm 3,281$ & $39,54 \pm 1,144$ & NS & / \\
\hline & Birth weight (grams) & $3338.42 \pm 503.95$ & $3450 \pm 418.221$ & NS & / \\
\hline & APGAR score $<7$ & $4.7 \%$ & $1.8 \%$ & 0,010 & 3,273 \\
\hline & Respiratory distress at birth & $7.3 \%$ & $1.8 \%$ & 0,004 & 5,635 \\
\hline \multirow{9}{*}{ 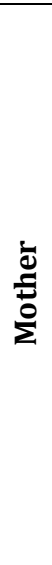 } & Malodorous and/or colored amniotic liquid & $54.8 \%$ & 0 & 0,000 & 1,793 \\
\hline & PROM $>12$ hours & $25.4 \%$ & 0 & 0,000 & 1,460 \\
\hline & PROM $>24$ hours & $14.7 \%$ & 0 & 0,001 & 1,408 \\
\hline & Maternal UTI & $46.3 \%$ & 0 & 0,000 & 1,676 \\
\hline & Maternal body temperature during delivery & $37.51 \pm 0.806$ & $37.32 \pm 0.471$ & NS & / \\
\hline & Hypothermia & $6,6 \%$ & $0 \%$ & / & \\
\hline & Hyperthermia & $2,2 \%$ & $0 \%$ & / & \\
\hline & Maternal hospitalization & $27.9 \%$ & $1.8 \%$ & 0,000 & 5,417 \\
\hline & Maternal antenatal antibiotic therapy & $27.1 \%$ & $7.1 \%$ & 0,001 & 8,590 \\
\hline
\end{tabular}

Many studies have consistently shown that the concentration of PCT in plasma of newborns and in cord blood were not affected by sex and were significantly higher in suspected groups in comparison with controls [31],[32]. We have found similar results in our study. These studies have also shown that birth weight and gestational age can both influence the concentration of PCT [17]. These results are in contrast with our results because we have excluded premature and very low birth weight newborns from our study.

In the present study, two newborns from the control group had a cord blood PCT level higher than the cut-off value $(0.595 \mathrm{ng} / \mathrm{mL})$. This could be due to physiological increase or may perhaps be caused by prenatal events other than 
infection. Investigators have also found that PCT is the best marker in the diagnosis of neonatal infections in comparison with many other biomarkers (IL-6, IL-8, CRP...etc). However, PCT reliability as a single biomarker of neonatal infections is limited by its nonspecific physiological elevation in healthy newborn within the first 48 hours of life [17],[28], which sometimes make the diagnosis difficult. A false increase of
PCT can be seen in some non-infectious perinatal conditions, such as neonatal respiratory distress syndrome, perinatal asphyxia, intracranial hemorrhage, circulatory failure and cardiopulmonary resuscitation [28]. Thus, the perinatal history must be taken into account before PCT concentrations can be properly interpreted during the first few days of life.

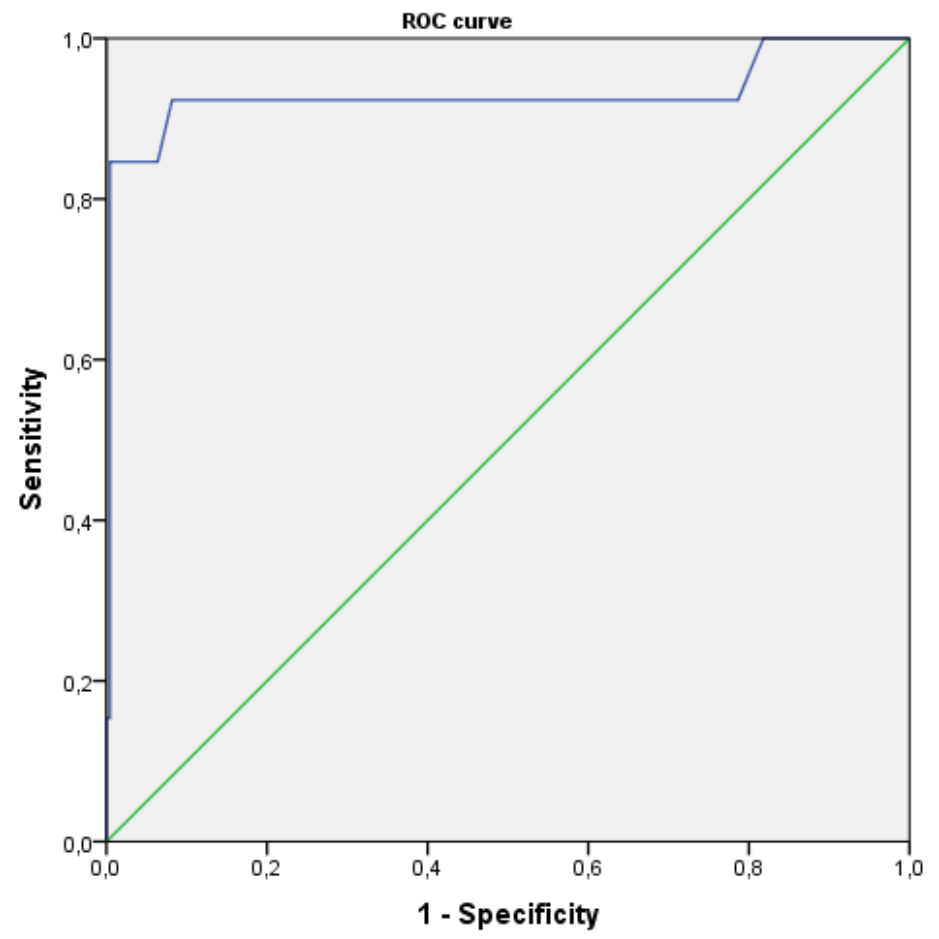

Figure 1: ROC curve of cord blood PCT to detect MFI at birth (area under the curve 0.93; SE 0.059; $p=0.000$ ).

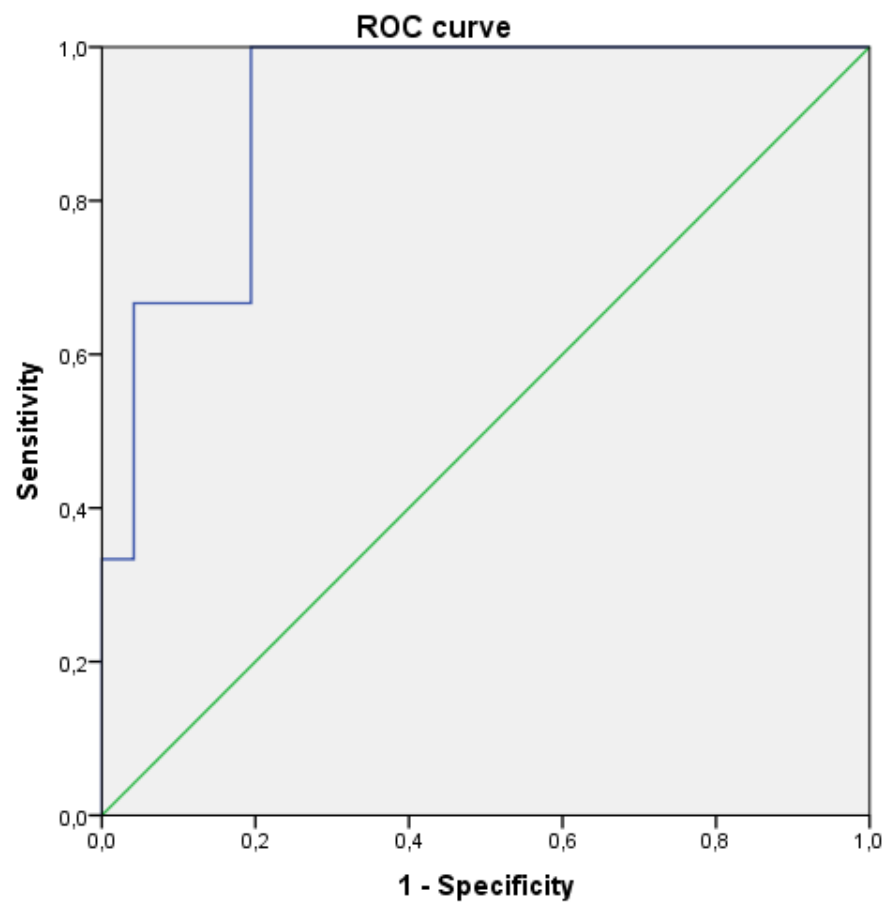

Figure 2: ROC curve of venous blood PCT to detect MFI at birth (area under the curve 0.921; SE 0.054; $p=0.014$ ). 
Probably when the newborn is exposed to microorganisms (prenatally or during delivery), the risk of maternofetal infections increase because the fetus could easily be contaminated in this situation [1] [2]. Many studies have shown the association of factors related to the mother such as chorioamnionitis, abnormal maternal body temperature preceding, during or succeeding delivery, premature rupture of membranes (PROM) more than 18 hours, urinary tract infection (UTI) with MFI [2] [6] [11] [14] [33]. In the group I of our study, we observed different risk factors; malodorous and/or colored amniotic liquid (54.8\%), PROM $\geq 12$ hours (25.4\%), PROM $\geq 24$ hours (14.7\%), UTI (46.3\%) and maternal abnormal body temperature during delivery (18.8\%). These characteristics are resumed in Table 1.

We also compared demographic variables among women with and without risk factors. The mean age of the mothers with risk factors was $28.87 \pm 6.29$ years with a parity of $1.08 \pm 1.37,49.5 \%$ were singleton pregnancies. $98.5 \%$ are housewives and $52.0 \%$ coming from rural areas. 9.7\% had a history of previous C-section delivery and $11.2 \%$ had an antecedent of abortion.

Mothers without any risk factor had a mean age of $29.43 \pm 5.56$ with a parity of $1.30 \pm 1.29,31.9 \%$ were singleton pregnancies. $89.3 \%$ of these women are housewives and $41.1 \%$ coming from rural areas. $10.1 \%$ had a history of previous C-section delivery and $23.2 \%$ had an antecedent of abortion.

The high rate of low socioeconomic status of studied mothers observed in this study could be due to the reason that the hospital where we conducted our study was free of charge. These mothers couldn't bear the high cost of private clinics.

Newborns born to housewive mothers $(\mathrm{p}=0,035)$ or mothers with malodorous and/or coloured amniotic liquid $(p=0,001)$, with hypertension $(p=0,032)$, hospitalized $(p=0,000)$ or received an antibiotherapy during the last term of pregnancy $(p=0,007)$ have a significantly higher level of PCT.

As regards to the maternal risk factors, risk of MFI was 1.4 times higher among neonates exposed to PROM. Also, there was a significant association between UTI, malodorous and/or coloured amniotic liquid and MFI as we found that the risk of infection is respectively about 1.6 and 1.7 times more among neonates born to mothers with a history of UTI or chorioamnionitis. Similarly, there was a very high significant association between hospitalization, maternal antibiotherapy during the last term of pregnancy, dystocia during delivery and MFI occurrence (OR $=5.417,8.590,2.519$ respectively). Low socioeconomic status is also strongly associated with MFI (OR =6.127).

Data from the several studies indicated that the use of antibiotics prenatally or perinatally in pregnant women can also affect the level of PCT and might decrease maternofetal infections [15]. A study on perinatal influence on PCT showed that antibiotic therapy was associated with false-negative PCT results [28]. Many similar cases were observed in our study.

\section{CONCLUSION}

Both cord blood PCT and venous blood PCT levels are significantly increased in MFI. Sensitivities are respectively, 92.3 and 100 percent. They showed specificities of 91.8 and 80.5 percent respectively. Thus, serum PCT or cord blood PCT can potentially be used to improve our management of newborns at risk.

\section{ACKNOWLEDGEMENT}

The study was supported by a grant from the Algerian ministry of health and population and from Ferhat Abbas University (UFAS-1). The authors acknowledge and thank the patient's parents and the staff of the hospital for their cooperation and appreciated help.

\section{CONFLICT OF INTEREST}

The authors declare no conflicts of interests.

\section{REFERENCES}

1. Vergnano S, Heath P. Fetal and neonatal infections. Medicine. 2017; 45(11):715-722.

2. Cortese F, Scicchitano P, Gesualdo M, Filaninno A, De Giorgi E, Schettini F et al. Early and Late Infections in Newborns: Where Do We Stand? A Review. Pediatrics \& Neonatology. 2016; 57(4):265-273.

3. Kan B, Razzaghian H, Lavoie P. An Immunological Perspective on Neonatal Sepsis. Trends in Molecular Medicine. 2016; 22(4):290-302.

4. Stronati M, Castagnoli R, Ioimo I, Achille C, Manzoni P, Tzialla C et al. Novel Approaches to the Study of Neonatal Infections. American Journal of Perinatology. 2018; 35(06):570-574.

5. Dramowski A, Velaphi S, Reubenson G, Bekker A, Perovic 0, Finlayson $\mathrm{H}$ et al. National Neonatal Sepsis Task Force launch: Supporting infection prevention and surveillance, outbreak investigation and antimicrobial stewardship in neonatal units in South Africa. South African Medical Journal. 2020; 110(5):360.

6. Khan A, Morris S, Bhutta Z. Neonatal and Perinatal Infections. Pediatric Clinics of North America. 2017; 64(4):785-798.

7. Vergnano S, Buttery J, Cailes B, Chandrasekaran R, Chiappini E, Clark E et al. Neonatal infections: Case definition and guidelines for data collection, analysis, and presentation of immunisation safety data. Vaccine. 2016; 34(49):6038-6046.

8. Chauhan N, Tiwari S, Jain U. Potential biomarkers for effective screening of neonatal sepsis infections: An overview. Microbial Pathogenesis. 2017; 107:234-242.

9. Van Herk W, Stocker M, van Rossum A. Recognising early onset neonatal sepsis: an essential step in appropriate antimicrobial use. Journal of Infection. 2016; 72:S77-S82.

10. Amess $P$, Rabe H, Wertheim D. Visual assessment of heart rate variability patterns associated with neonatal infection in preterm infants. Early Human Development. 2019; 134:31-33.

11. Wortham J, Hansen N, Schrag S, Hale E, Van Meurs K, Sánchez P et al. Chorioamnionitis and Culture-Confirmed, Early-Onset Neonatal Infections. Pediatrics. 2015; 137(1):e20152323.

12. Carr D, Barnes E, Gordon A, Isaacs D. Effect of antibiotic use on antimicrobial antibiotic resistance and late-onset neonatal infections over 25 years in an Australian tertiary neonatal unit. Archives of Disease in Childhood - Fetal and Neonatal Edition. 2016; 102(3):F244-F250.

13. Hao W, Song J, Li G, Han B. Procalcitonin and C-reactive protein in neonatal infection, a comparison study between intrauterine infection and non-intrauterine infection. Biomedical Research. 2017; 28(14):6256- 6259.

14. Huang F, Chen H, Yang P, Lin H. Bird's Eye View of a Neonatologist: Clinical Approach to Emergency Neonatal Infection. Pediatrics \& Neonatology. 2016; 57(3):167-173.

15. Tang Z, Qin D, Tao M, Lv K, Chen S, Zhu X et al. Examining the utility of the CD64 index compared with other conventional indices for early diagnosis of neonatal infection. Scientific Reports. 2018; 8(1).

16. Sharma D, Farahbakhsh N, Shastri S, Sharma P. Biomarkers for diagnosis of neonatal sepsis: a literature review. The Journal of Maternal-Fetal \& Neonatal Medicine. 2017; 31(12):1646-1659.

17. Eschborn S, Weitkamp J. Procalcitonin versus C-reactive protein: review of kinetics and performance for diagnosis of neonatal sepsis. Journal of Perinatology. 2019; 39(7):893-903.

18. Pontrelli G, De Crescenzo F, Buzzetti R, Calò Carducci F, Jenkner A, Amodio D et al. Diagnostic value of soluble triggering receptor expressed on myeloid cells in paediatric sepsis: a systematic review. Italian Journal of Pediatrics. 2016; 42(1).

19. Delanghe J, Speeckaert M. Translational research and biomarkers in neonatal sepsis. Clinica Chimica Acta. 2015; 451:46-64. 
20. Markic J, Saraga M, Dahlem P. Sepsis Biomarkers in Neonates and Children: C-Reactive Protein and Procalcitonin. Journal of Child Science. 2017; 07(01):e89-e95.

21. Dapaah-Siakwan, F., Mehra, S., Lodhi, S., Mikhno, A., Cameron, G. White Cell Indices and CRP: Predictors of Meningitis in Neonatal Sepsis?. International Journal of Pediatrics, 2016; 4(2):13551364.

22. Brown J, Meader N, Cleminson J, McGuire W. C-reactive protein for diagnosing late-onset infection in newborn infants. Cochrane Database of Systematic Reviews. 2019; 14(1):1.

23. Pontrelli G, De Crescenzo F, Buzzetti R, Jenkner A, Balduzzi S, Calò Carducci $\mathrm{F}$ et al. Accuracy of serum procalcitonin for the diagnosis of sepsis in neonates and children with systemic inflammatory syndrome: a meta-analysis. BMC Infectious Diseases. 2017; 17(1).

24. Hooven, T. A., Polin, R. A. Neonatal Bacterial Infections. In Common Problems in the Newborn Nursery. Springer, Cham. 2019:71-80

25. Hendricks-Munoz K, Xu J, Mally P. Biomarkers for neonatal sepsis: recent developments. Research and Reports in Neonatology. 2014; 157.

26. Mathur N, Behera B. Blood Procalcitonin Levels and Duration of Antibiotics in Neonatal Sepsis. Journal of Tropical Pediatrics. 2018; 65(4):315-320.

27. Iskandar A, Arthamin M, Indriana K, Anshory M, Hur M, Di Somma S. Comparison between presepsin and procalcitonin in early diagnosis of neonatal sepsis. The Journal of Maternal-Fetal \& Neonatal Medicine. 2018; 32(23):3903-3908.

28. Pravin Charles M, Kalaivani R, Venkatesh S, Kali A, Seetha K. Evaluation of procalcitonin as a diagnostic marker in neonatal sepsis. Indian Journal of Pathology and Microbiology. 2018; 61(1):81.

29. Brodska H, Valenta J, Pelinkova K, Stach Z, Sachl R, Balik M et al. Diagnostic and prognostic value of presepsin vs. established biomarkers in critically ill patients with sepsis or systemic inflammatory response syndrome. Clinical Chemistry and Laboratory Medicine (CCLM). 2018; 56(4):658-668.

30. Montaldo P, Rosso R, Santantonio A, Chello G, Giliberti P. Presepsin for the detection of early-onset sepsis in preterm newborns. Pediatric Research. 2016; 81(2):329-334.

31. Nakstad B. The diagnostic utility of procalcitonin, interleukin6 and interleukin-8, and hyaluronic acid in the Norwegian consensus definition for early-onset neonatal sepsis (EONS). Infection and Drug Resistance. 2018; 11:359-368.

32. Yang A, Liu J, Yue L, Wang H, Yang W, Yang G. Neutrophil CD64 combined with PCT, CRP and WBC improves the sensitivity for the early diagnosis of neonatal sepsis. Clinical Chemistry and Laboratory Medicine (CCLM). 2016; 54(2).

33. Ranosiarisoa Z, El Harrif S, Andrianirina A, Duron S, SimonGhediri M, Ramparany L et al. Epidemiology of Early-onset Bacterial Neonatal Infections in Madagascar. The Pediatric Infectious Disease Journal. 2019; 38(1):76-81. 